\title{
Prevalence and associations of overweight among adult women in Sri Lanka: a national survey
}

\author{
Renuka Jayatissa ${ }^{1}$, S M Moazzem Hossain ${ }^{2}$, Sandya Gunawardana ${ }^{1}$, J M Ranbanda ${ }^{1}$, Malsha \\ Gunathilaka ${ }^{1}$, P C De Silva ${ }^{1}$
}

Sri Lanka Journal of Diabetes, Endocrinology and Metabolism 2012; 2: 61-68

\begin{abstract}
The rates of overweight and obesity are rising to epidemic proportions, especially among women. There are many health risks associated with increased weight. This study aims at providing information on the overweight and obesity and its associated factors among non pregnant and non lactating women aged 15 to 49 years in Sri Lanka. Multistage cluster sampling method was used. A household survey was carried out in nine districts, each randomly selected from all 9 provinces. Thirty Grama Nildhari areas per district were selected, each cluster consisting of 21 randomly selected households. Data collection was by an interviewer administered questionnaire. Weight and height were measured and body mass index (BMI) calculated. International classification was used to identify overweight women. Total of 6071 households were included in the study. Of the 27,862 residents in the selected households, 27.3 percent were women aged between 15 and 49 years. Of them, 18.2\% had BMI $<18.5$ (thin), 52.4\% were BMI between 18.5-24.9 (normal), 22.8\% were between 25.0 and 29.9 (overweight) and 6.6\% were BMI 30.0 or above (obese). When Asian cutoff value is applied 37.8\% (BMI 18.5-23.0), 28.7\% (BMI 23.01-27.5) and 15.2\% (BMI>27.5) were normal, overweight and obese respectively. Higher level of husband's education and higher wealth quintiles were associated with risk of overweight or obesity. Increasing level of overweight and obesity prevalence among women between 15-49 years indicates the important role of health professionals in promoting preventative measures and encouraging positive lifestyle behaviors of women during health encounters. We recommend counseling women about safe and effective weight loss and weight management programs.
\end{abstract}

\section{Introduction}

Worldwide, at least 2.8 million people die each year as a result of being overweight or obese. Risks of coronary heart disease, ischemic stroke and type 2 diabetes mellitus increase steadily with increasing body mass index (BMI), a measure of weight relative to height. Raised body mass index also increases the risk of cancer of the breast, colon, prostate, endometrium, kidney and gall bladder. Mortality rates increase with increasing degrees of overweight, as measured by BMI. To achieve optimum health, the median BMI for an adult population should be in the range of 21 to $23 \mathrm{~kg} / \mathrm{m}^{2}$, while the goal for individuals should be to maintain body mass index in the range 18.5 to 24.9 $\mathrm{kg} / \mathrm{m}^{2}$. There is increased risk of co-morbidities for body mass index 25.0 to 29.9, and moderate to severe risk of co-morbidities for body mass index greater than 30 (1).

The prevalence of overweight and obesity were highest in the WHO Regions of the Americas (62\% for overweight in both sexes, and 26\% for obesity) and lowest in the WHO Region for South East Asia (14\% overweight in both sexes and 3\% for obesity). In all WHO regions women were more likely to be obese than men. In the WHO regions for Africa, Eastern Mediterranean and South East Asia, women had roughly doubled the obesity prevalence of men (1).

Sri Lanka is not an exception regarding overweight and obesity. Demographic and Health Survey (DHS) in 2000 and $2006 / 7$ found $24 \%$ and $31.2 \%$ of women were overweight respectively $(2,3)$. Among adults, a study took place at the national level in 2005/6 and found the prevalence of overweight for both genders $(n=4532)$ was $25.2 \%$ (4).

In accordance with the nutrition policy of Sri Lanka, national priorities in research encompassed the identification of the problem of overweight among the Sri Lankan population and its geographical, sex, and socioeconomic distribution (5).

The objective of this study was to (i) estimate the prevalence and distribution of overweight and obesity, in adult females and (ii) to analyze its possible causes. 


\section{Materials and methods}

Muti-stage cluster sampling method was used to select a representative sample at national level. A cross sectional household survey was carried out in nine districts of Sri Lanka, one district randomly selected from each province. Each district constituted one study area, except the Colombo district which had two study areas: the Colombo Municipal Council area (Colombo MC) and the Colombo Regional Director of Health Services (RDHS) area. The selected study areas were Jaffna, Trincomalee, Colombo MC, Colombo RD, Kurunegala, Anuradhapura, Nuwara Eliya, Badulla, Ratnapura and Hambantota districts.

The probability proportional to size sampling technique was used to identify the clusters which are defined at the Grama Niladhari (GN) division level. The first cluster was identified randomly, followed by identification of a total of 30 clusters per district, using the sampling interval. A systematic random sampling technique was used within each cluster to identify 21 households. Each GN area was divided into several blocks, including 100 households per block. One block was randomly selected to collect the samples. A household was defined as persons routinely sharing food from the same cooking pot and living in the same compound or physical location. The first household was selected randomly and after that every third household was visited. The estimated sample size per district was 617 households totaling to 6170 households in the 10 study areas. Non pregnant and non lactating women between $15-49$ years living in the selected households were included. A pregnant woman was defined as any reported pregnancy by the women and a lactating woman was defined as woman with a live birth within the previous 6 months.

The household survey included the administration of a pre-tested questionnaire, assessment of the nutritional status of women using anthropometric indicators which was done using standardized procedures for measuring the height and weight (6). Height was recorded to the nearest $0 \cdot 1 \mathrm{~cm}$, using UNICEF stadiometers. Body weight was measured to the nearest $0 \cdot 1 \mathrm{~kg}$ using a SECA digital UNICEF weighing scales.

Data analysis was conducted in SPSS software packages. Body mass index (BMI) was calculated using weight and height. Four categories of women were identified based on BMI - thin $(<18.5)$, normal (18.5-24.9), overweight ( $\geq 25.0-29.9)$ and obese $(\geq 30.0)$ (7). Asian cutoff was also applied to assess the BMI categories as follows; BMI - thin (<18.5), normal (18.5-23.0), overweight (23.0127.5 ) and obese ( $\geq 27.5$ ) (7). For detail analysis international BMI cutoff values were used for comparative purposes. Multiple logistic regression analysis was used to determine the factors associated with overweight or obesity in women of $15-49$ years of age. The magnitude of association was expressed as adjusted Odds Ratio (OR) and 95 percent confidence interval (95\%CI) with the p value $<0.05$ for statistical significance.
Two indicators of economic status were used in this study, the first being the average household income per month and the second, the household wealth index. Household income was categorized into 6 classes considering the class limits of the income deciles described in the Household Income and Expenditure Survey, 2007 (8) and adequacy of the number of observations in each class-interval.

The 'household wealth index' was developed using 3 sources of information: housing characteristics, household possessions and availability of water and sanitation facilities. Principal component analysis was performed by using information on the ownership of household goods and amenities (assets) to assign weights to each household asset, and obtain wealth scores for each household in the sample. The sample was then divided into five groups of equal size, from the poorest quintile to the richest quintile, based on the wealth scores of households they were living in. The wealth index is assumed to capture the underlying long-term wealth through information on the household assets, and is intended to produce a ranking of households by wealth, from poorest to richest. The study was carried out during the period, January to April 2009.

\section{Results}

A total of 6071 households were included in the survey. Out of the total, 69.4 percent of the households were in the rural sector, 25.0 percent in the urban sector and 5.6 percent in the estate sector. Of the total 27,862 individuals who were usually resident in the selected households, 7604 (27.3 percent) were women aged between 15.0 and 49.9 years (Table 1 ).

Thirty nine percent of the households had a monthly income less than Rs.9000 and 8.5\% had Rs. $\geq 32,000$. Percentage of households classified as belonging to the lowest wealth quintile varied from 4.6 percent in the Colombo district to 40 percent in Jaffna district. Conversely, households belonging to the highest wealth quintile ranged from 5.1 percent in Jaffna to 46.6 percent in Colombo district (Table 2).

A total of 2146 non-pregnant and non lactating women aged between 15 to 49 years were included in the assessment of body mass index. As shown in Figure 1, of the total sample, 18.2 percent had BMI less than 18.5 (thin), 52.6 percent had BMI between 18.5 and 24.9 (normal), 22.5 percent with values between 25 and 29 (overweight) and 6.7 percent, with BMI values 30 or above (obese). When the Asian cutoff was applied 18.2 percent had BMI less than 18.5 (thin), 37.8 percent had BMI between 18.5 and 23.0 (normal), 28.7 percent with values between 23.01 and 27.5 (overweight) and 15.2 percent, with BMI values above 27.5 above (obese). 
Table 1. Distribution of women 15-49 years by sector and district

\begin{tabular}{|c|c|c|c|}
\hline \multirow[t]{2}{*}{ Sector/ District } & \multirow[t]{2}{*}{ Total Number of individuals } & \multicolumn{2}{|c|}{ Women 15.0-49.9 years } \\
\hline & & No. & $\%$ \\
\hline \multicolumn{4}{|l|}{ Sector } \\
\hline Urban & 7130 & 1897 & 26.6 \\
\hline Rural & 18960 & 5251 & 27.7 \\
\hline Estate & 1772 & 456 & 25.7 \\
\hline \multicolumn{4}{|l|}{ District } \\
\hline Anuradhapura & 2676 & 775 & 29.0 \\
\hline Badulla & 2869 & 769 & 26.8 \\
\hline Colombo RD & 2780 & 746 & 26.8 \\
\hline Colombo MC & 3017 & 799 & 26.5 \\
\hline Hambantota & 2717 & 733 & 27.0 \\
\hline Jaffna & 2776 & 763 & 27.5 \\
\hline Kurunegala & 2801 & 775 & 27.7 \\
\hline Nuwara Eliya & 2789 & 756 & 27.1 \\
\hline Ratnapura & 2893 & 802 & 27.7 \\
\hline Trincomalee & 2544 & 687 & 27.0 \\
\hline Total & 27862 & 7604 & 27.3 \\
\hline
\end{tabular}

Table 2. Distribution of households according to income and wealth index, by district

\begin{tabular}{|c|c|c|c|c|c|c|c|c|c|c|c|c|}
\hline \multirow{3}{*}{ Characteristic } & \multicolumn{10}{|c|}{$\%$ within district } & & \\
\hline & \multirow{2}{*}{$\begin{array}{l}\sigma \\
\vdots \\
\vdots \\
\vdots \\
\frac{0}{\Xi} \\
\vdots \\
\vdots \\
\vdots \\
\vdots\end{array}$} & \multirow{2}{*}{ 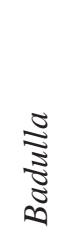 } & \multirow{2}{*}{$\frac{8}{\frac{8}{5}}$} & \multirow{2}{*}{ 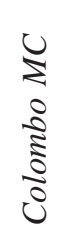 } & \multirow{2}{*}{ 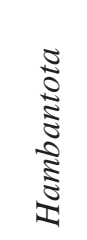 } & \multirow{2}{*}{ 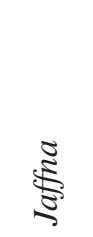 } & \multirow{2}{*}{ 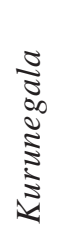 } & \multirow{2}{*}{ 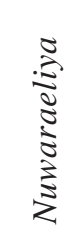 } & \multirow{2}{*}{ 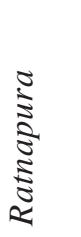 } & \multirow{2}{*}{ 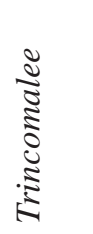 } & \multicolumn{2}{|c|}{ All Districts } \\
\hline & & & & & & & & & & & No. & $\%$ \\
\hline \multicolumn{13}{|l|}{$\begin{array}{l}\text { Monthly } \\
\text { household } \\
\text { income (LKR) }\end{array}$} \\
\hline$<9,000$ & 32.6 & 55.0 & 16.6 & 17.3 & 39.5 & 59.8 & 32.6 & 44.1 & 51.7 & 41.1 & 2311 & 39.1 \\
\hline $9,000-13,999$ & 13.9 & 15.6 & 18.9 & 19.6 & 19.0 & 17.3 & 20.3 & 23.5 & 17.4 & 19.1 & 1090 & 18.4 \\
\hline 14,000 - 19,999 & 18.2 & 9.5 & 17.6 & 22.7 & 17.8 & 11.4 & 15.9 & 15.4 & 12.0 & 22.2 & 957 & 16.2 \\
\hline 20,000 - 31,999 & 25.0 & 14.6 & 28.9 & 26.1 & 16.1 & 9.2 & 18.6 & 13.4 & 12.5 & 13.8 & 1057 & 17.9 \\
\hline$\geq 32,000$ & 10.3 & 5.3 & 17.9 & 14.4 & 7.6 & 2.2 & 12.5 & 3.6 & 6.4 & 3.8 & 502 & 8.5 \\
\hline \multicolumn{13}{|l|}{$\begin{array}{l}\text { Wealth Index } \\
\text { Quintile }\end{array}$} \\
\hline Lowest & 19.0 & 22.3 & 4.6 & 6.4 & 17.3 & 40.0 & 10.5 & 32.4 & 22.8 & 26.4 & 1214 & 20.0 \\
\hline Second & 17.8 & 25.4 & 8.8 & 10.5 & 16.6 & 26.6 & 16.5 & 32.1 & 17.1 & 29.6 & 1210 & 20.0 \\
\hline Middle & 20.1 & 22.5 & 14.7 & 15.0 & 18.6 & 18.8 & 25.7 & 19.7 & 24.4 & 21.3 & 1219 & 20.0 \\
\hline Fourth & 22.1 & 17.2 & 25.2 & 31.3 & 24.2 & 9.6 & 24.4 & 9.8 & 20.0 & 15.0 & 1214 & 20.0 \\
\hline Highest & 21.0 & 12.6 & 46.6 & 36.7 & 23.4 & 5.1 & 23.0 & 6.1 & 15.7 & 7.7 & 1214 & 20.0 \\
\hline
\end{tabular}




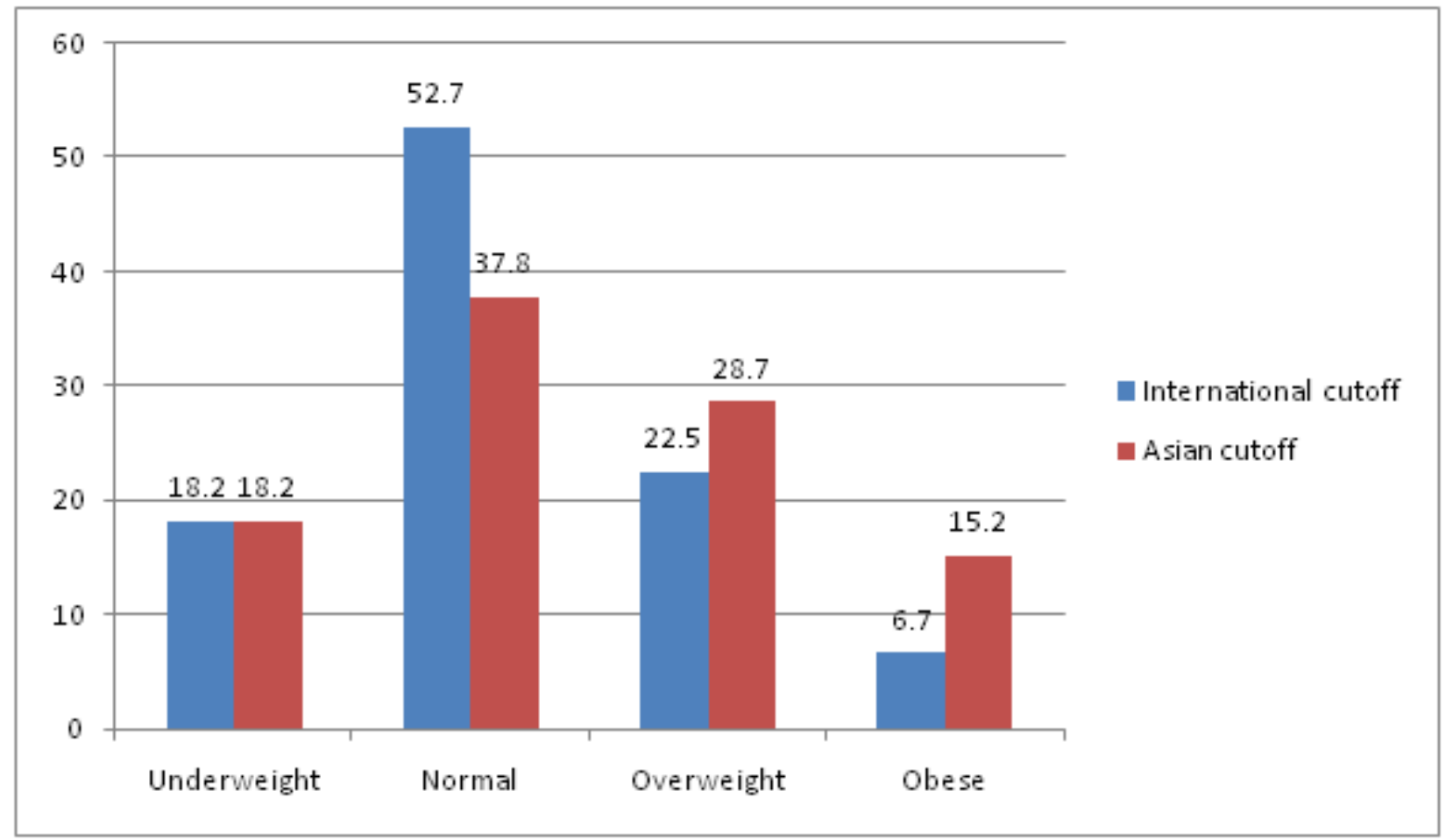

Figure 1. Distribution of non-pregnant women 15-49 years by BMI levels applying international and Asian cutoff.

Available national data for non pregnant women aged 15-49 years showed a rising trend in overweight prevalence over time with falling rates in underweight prevalence. Rates of increase seems most marked from 2000 to 2006 (Figure 2). It is interesting to note that the percentage of category of women within the normal BMI levels were almost the same.

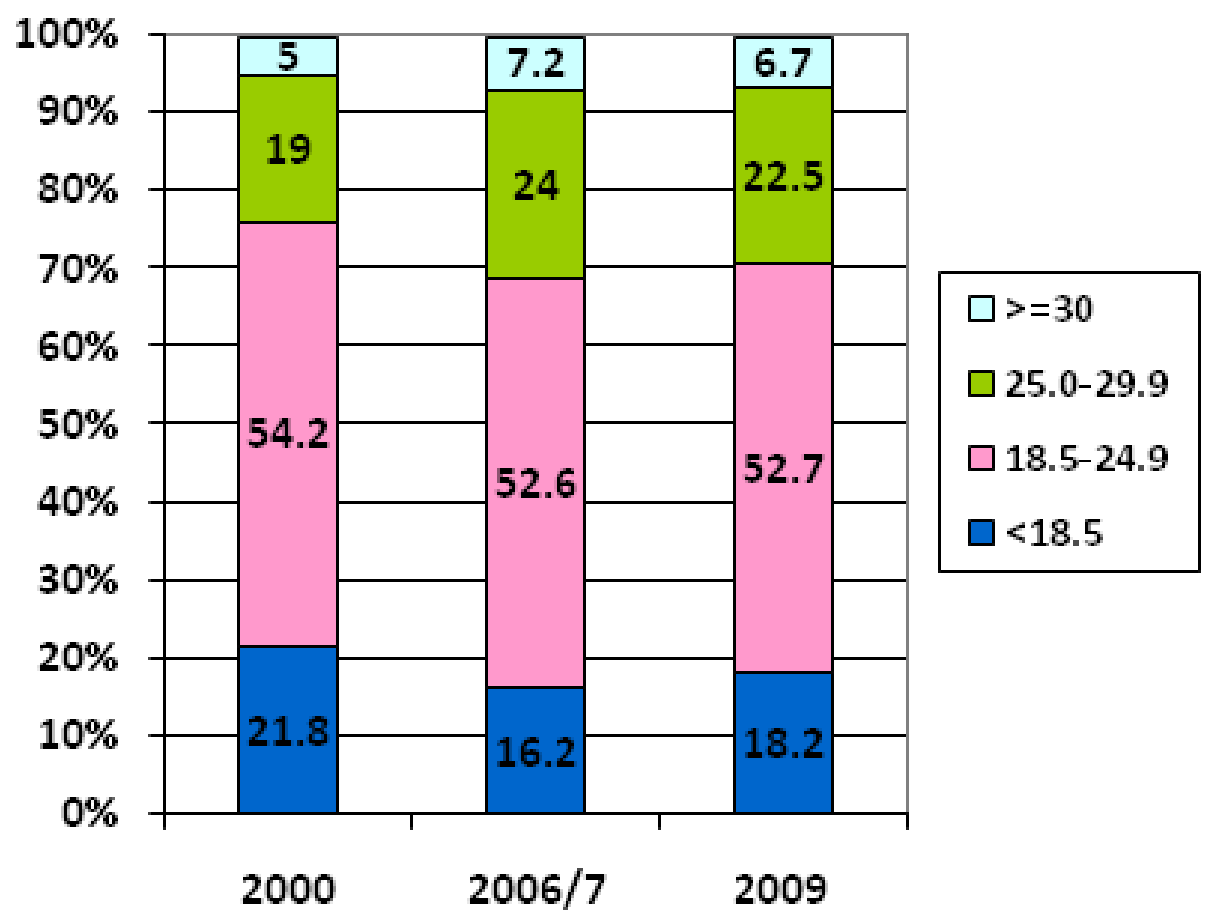

Figure 2. Pattern of distribution of BMI in non pregnant women aged 15-49 years in Sri Lanka from 2000-2009. 
The prevalence of underweight (BMI less than 18.5) was high in the 15-19 age group (40.5 percent) with a substantial decline in the age groups 20-29 years (22.5 percent) and 30-39 years (12.9 percent). Of all non-pregnant and non lactating women studied, 29.2 percent were either overweight or obese. This percentage increased with increasing age, most marked after 30 years of age (Table 3).

Table 3. Prevalence of thin, normal and overweight/obese in non-pregnant women by background characteristics

\begin{tabular}{|c|c|c|c|c|c|}
\hline \multirow[b]{2}{*}{$\begin{array}{l}\text { Background } \\
\text { Characteristics }\end{array}$} & \multicolumn{4}{|c|}{ BMI category (\%) } & \multirow[b]{2}{*}{ Total } \\
\hline & $\begin{array}{l}\text { Underweight } \\
(B M I<18.5)\end{array}$ & $\begin{array}{c}\text { Normal } \\
(B M I=18.5-24.9)\end{array}$ & $\begin{array}{c}\text { Overweight } \\
B M I=25.0-29.0)\end{array}$ & $\begin{array}{c}\text { Obese } \\
(B M I>30.0)\end{array}$ & \\
\hline \multicolumn{6}{|l|}{ Age group (years) } \\
\hline $15-19$ & 40.5 & 45.2 & 14.3 & 0.0 & 84 \\
\hline $20-29$ & 22.5 & 54.7 & 18.1 & 4.8 & 922 \\
\hline $30-39$ & 12.9 & 51.8 & 26.6 & 8.7 & 929 \\
\hline $40-49$ & 14.2 & 50.7 & 26.5 & 8.5 & 211 \\
\hline \multicolumn{6}{|l|}{ Sector } \\
\hline Urban & 11.3 & 45.4 & 28.3 & 15.0 & 533 \\
\hline Rural & 18.7 & 55.5 & 21.6 & 4.2 & 1491 \\
\hline Estate & 42.6 & 50.0 & 7.4 & 0.0 & 122 \\
\hline \multicolumn{6}{|l|}{ District } \\
\hline Anuradhapura & 16.9 & 53.7 & 26.4 & 3.0 & 201 \\
\hline Badulla & 24.1 & 51.7 & 19.8 & 4.3 & 232 \\
\hline Colombo & 12.1 & 52.8 & 27.1 & 7.9 & 214 \\
\hline Colombo MC & 9.6 & 38.4 & 32.3 & 19.7 & 229 \\
\hline Hambantota & 20.4 & 52,6 & 22.3 & 4.7 & 211 \\
\hline Jaffna & 20.5 & 57.7 & 15.5 & 6.4 & 220 \\
\hline Kurunegala & 19.2 & 49.5 & 25.3 & 6.0 & 182 \\
\hline Nuwaraeliya & 22.5 & 59.9 & 11.8 & 5.9 & 187 \\
\hline Ratnapura & 25.3 & 56.5 & 17.3 & 0.8 & 237 \\
\hline Trincomalee & 12.0 & 54.5 & 26.2 & 7.3 & 233 \\
\hline \multicolumn{6}{|c|}{ Women's education level } \\
\hline no schooling & 20.0 & 58.2 & 18.2 & 3.6 & 55 \\
\hline primary & 23.4 & 52.5 & 19.0 & 5.1 & 158 \\
\hline Secondary & 18.1 & 49.5 & 24.2 & 8.3 & 678 \\
\hline Passed GCE (O/L) & 18.5 & 54.2 & 21.7 & 5.7 & 757 \\
\hline Higher & 15.2 & 54.1 & 23.9 & 6.7 & 460 \\
\hline \multicolumn{6}{|c|}{ Monthly household income } \\
\hline$<9,000$ & 21.9 & 52.4 & 21.4 & 4.3 & 748 \\
\hline $9,000-13,999$ & 15.9 & 55.4 & 21.6 & 7.1 & 408 \\
\hline $14,000-19,999$ & 12.2 & 56.8 & 25.5 & 5.5 & 329 \\
\hline $20,000-31,999$ & 16.0 & 49.1 & 24.3 & 10.6 & 350 \\
\hline$\geq 32,000$ & 9.6 & 51.4 & 28.8 & 10.3 & 146 \\
\hline \multicolumn{6}{|c|}{ Wealth index quintiles } \\
\hline Poorest & 26.2 & 57.4 & 13.9 & 2.5 & 432 \\
\hline Second & 22.2 & 53.2 & 19.0 & 5.7 & 406 \\
\hline Middle & 19.4 & 50.0 & 24.3 & 6.3 & 412 \\
\hline Fourth & 13.2 & 52.4 & 25.8 & 8.6 & 418 \\
\hline Richest & 11.1 & 50.4 & 28.7 & 9.8 & 478 \\
\hline Overall & 18.2 & 52.7 & 22.5 & 6.7 & 2146 \\
\hline
\end{tabular}


Marked inter-sectoral differences were seen, with the estate sector showing the highest percentage (42.6 percent) of women with BMI less than 18.5, compared to 11.3 percent in the urban sector. Conversely, in the urban sector, there was a high percentage of women who were overweight (28.3\%) and obese (15.0\%).

Comparison between districts show that the percentage with low BMI ranged from 12.1 percent in Colombo RD to 25.3 percent in Ratnapura. Conversely, overweight ranged from 11.8 percent in NuwaraEliya district and 32.3 percent in Colombo MC. Obesity varied from 0.8 percent in Ratnapura district to 19.7 percent in Colombo MC. There was a declining pattern in the prevalence of underweight with increasing income levels and wealth quintiles. The prevalence of overweight and obesity showed an increase with higher income levels and wealth quintiles.

As shown in Table 4, Overweight and/or obesity in women were significantly higher after 30 years of age, in the urban sector, Colombo MC and Colombo RD, highest income and wealth quintiles.

Table 4. Prevalence (95\% confidence interval), odds ratio (95\% confidence interval), and significance testing (p values) of overweight and obesity in non-pregnant and non lactating women by background characteristics

\begin{tabular}{|c|c|c|c|c|c|c|c|}
\hline \multirow[b]{2}{*}{ Characteristic } & \multicolumn{7}{|c|}{ Overweight / Obese BMI $\geq 25.0$} \\
\hline & $\%$ & \multicolumn{2}{|c|}{$95 \% C I$} & $O R$ & \multicolumn{2}{|c|}{$95 \% C I$} & $p$ value \\
\hline \multicolumn{8}{|c|}{ Women's age in yrs } \\
\hline$<20$ & 14.3 & 8.3 & 23.5 & 1.00 & & & \\
\hline $20-29$ & 22.9 & 20.3 & 25.7 & 1.12 & 0.50 & 2.55 & 0.779 \\
\hline 30-39 & 35.3 & 32.3 & 38.4 & 2.08 & 0.92 & 4.70 & 0.080 \\
\hline $40-49$ & 35.1 & 28.9 & 41.8 & 1.90 & 0.80 & 4.47 & 0.143 \\
\hline \multicolumn{8}{|c|}{ No. of children less than 5 years } \\
\hline 1 & 28.2 & 24.4 & 32.3 & 1.00 & & & \\
\hline 2 & 29.8 & 25.8 & 34.0 & 0.86 & 0.65 & 1.14 & 0.304 \\
\hline$\geq 3$ & 33.2 & 30.0 & 36.7 & 1.02 & 0.80 & 1.30 & 0.870 \\
\hline \multicolumn{8}{|l|}{ Sector } \\
\hline Urban & 43.3 & 39.1 & 47.5 & 1.00 & & & \\
\hline Rural & 25.9 & 23.8 & 28.2 & 0.72 & 0.50 & 1.03 & 0.072 \\
\hline Estate & 7.4 & 3.9 & 13.6 & 0.21 & 0.09 & 0.49 & 0.000 \\
\hline \multicolumn{8}{|l|}{ District } \\
\hline Anuradhapura & 29.4 & 23.5 & 36.0 & 1.00 & & & \\
\hline Badulla & 24.5 & 19.4 & 30.4 & 0.67 & 0.38 & 1.17 & 0.157 \\
\hline Colombo & 35.0 & 28.9 & 41.7 & 0.56 & 0.33 & 0.97 & 0.039 \\
\hline Colombo MC & 51.5 & 45.1 & 57.9 & 0.53 & 0.34 & 0.82 & 0.004 \\
\hline Hambantota & 27.0 & 21.4 & 33.4 & 0.57 & 0.32 & 1.00 & 0.048 \\
\hline Jaffna & 22.2 & 17.2 & 28.1 & 0.50 & 0.28 & 0.89 & 0.019 \\
\hline Karunegala & 31.3 & 25.0 & 38.4 & 0.69 & 0.39 & 1.21 & 0.197 \\
\hline Nuwara Eliya & 17.6 & 12.8 & 23.8 & 0.63 & 0.35 & 1.15 & 0.132 \\
\hline Ratnapura & 18.1 & 13.7 & 23.6 & 0.46 & 0.26 & 0.82 & 0.008 \\
\hline Trincomalee & 33.8 & 28.0 & 40.1 & 0.95 & 0.56 & 1.61 & 0.842 \\
\hline \multicolumn{8}{|c|}{ Mother's education } \\
\hline No schooling & 23.2 & 14.0 & 36.0 & 1.00 & & & \\
\hline Primary & 24.4 & 18.3 & 31.6 & 0.72 & 0.28 & 1.86 & 0.498 \\
\hline Secondary & 32.4 & 29.0 & 36.1 & 1.02 & 0.42 & 2.51 & 0.964 \\
\hline Passed O’ Level & 27.3 & 24.3 & 30.6 & 0.80 & 0.32 & 1.99 & 0.633 \\
\hline Higher & 30.7 & 26.6 & 35.0 & 0.73 & 0.29 & 1.84 & 0.503 \\
\hline
\end{tabular}


Overweight / Obese BMI $\geq 25.0$

\begin{tabular}{|c|c|c|c|c|c|c|c|}
\hline \multirow{2}{*}{$\begin{array}{l}\text { Characteristic } \\
\text { Husbands' education }\end{array}$} & \multirow[t]{2}{*}{$\%$} & \multicolumn{2}{|c|}{$95 \% C I$} & \multirow[t]{2}{*}{ OR } & \multicolumn{2}{|c|}{$95 \% C I$} & \multirow[t]{2}{*}{$p$ value } \\
\hline & & & & & & & \\
\hline No schooling & 13.8 & 7.0 & 25.2 & 1.00 & & & \\
\hline Primary & 24.2 & 19.4 & 29.6 & 2.78 & 1.07 & 7.20 & 0.035 \\
\hline Secondary & 31.2 & 28.0 & 34.6 & 3.37 & 1.34 & 8.50 & 0.010 \\
\hline Passed O’ Level & 31.8 & 28.7 & 35.1 & 3.46 & 1.38 & 8.72 & 0.008 \\
\hline Higher & 37.5 & 25.1 & 51.9 & 3.79 & 1.25 & 11.43 & 0.018 \\
\hline \multicolumn{8}{|c|}{ Household Income } \\
\hline$<9,000$ & 25.7 & 22.7 & 29.0 & 1.00 & & & \\
\hline $9,000-13,999$ & 28.8 & 24.6 & 33.4 & 0.95 & 0.70 & 1.28 & 0.714 \\
\hline 14,000 - 19,999 & 31.0 & 26.2 & 36.2 & 0.83 & 0.59 & 1.17 & 0.283 \\
\hline 20,000 - 31,999 & 35.0 & 30.2 & 40.2 & 0.78 & 0.56 & 1.09 & 0.147 \\
\hline$\geq 32,000$ & 39.0 & 31.5 & 47.2 & 0.88 & 0.56 & 1.40 & 0.593 \\
\hline \multicolumn{8}{|l|}{ Wealth Index } \\
\hline Poorest & 16.4 & 13.2 & 20.2 & 1.00 & & & \\
\hline Lower & 24.8 & 20.9 & 29.2 & 1.40 & 0.96 & 2.04 & 0.080 \\
\hline Middle & 30.6 & 26.3 & 35.2 & 1.58 & 1.07 & 2.33 & 0.020 \\
\hline Upper & 34.8 & 30.4 & 39.4 & 1.98 & 1.34 & 2.93 & 0.001 \\
\hline Highest & 38.3 & 34.1 & 42.8 & 2.07 & 1.35 & 3.19 & 0.001 \\
\hline Overall & 29.2 & 27.3 & 31.2 & & & & \\
\hline
\end{tabular}

Women in the estate sector had lower $(\mathrm{OR}=0.21)$ risk of being overweight/obese compared to urban sector. Compared to the Colombo MC, risk of overweight/obesity was low in certain districts: Ratnapura $(\mathrm{OR}=0.46)$, Jafffna $(\mathrm{OR}=0.50)$, Colombo RD (OR=0.53), Hambantota $(\mathrm{OR}=0.57)$, and Badulla (OR=0.56). Increasing level of husband's education and wealth quintiles were strong correlates for the risk of having overweight/obesity in women.

\section{Discussion}

In 2008, 35\% of adults aged 20+ were overweight (BMI $\geq 25 \mathrm{~kg} / \mathrm{m}^{2}$ ) (34\% men and 35\% of women) in the world. The worldwide prevalence of obesity has more than doubled between 1980 and 2008. In 2008, 10\% of men and $14 \%$ of women in the world were obese (BMI $\geq 30 \mathrm{~kg} / \mathrm{m}^{2}$ ), compared with $5 \%$ for men and $8 \%$ for women in 1980. An estimated 205 million men and 297 million women over the age of 20 were obese - a total of more than half a billion adults worldwide.

Data from Sri Lanka Demographic and Health Survey (DHS) 2000 and 2006/07 were taken for comparison of the nutritional status of women due to similar target groups used in the present study and DHS study. It was considered, useful to compare the main findings as both studies were based on large household samples, using the same indicators and methods in the assessment of nutritional status and were carried out within a last 10 year period.

The present study shows that 22.5 percent and 6.7 percent of women aged 15-49 years were overweight and obese respectively. Comparable data from DHS 2006/07 indicate the prevalence of overweight and obesity being 24.0 and 7.2 percent, respectively. This reduction of overweight and obese percentages in women in the present study may be due to the exclusion of lactating mothers. Using the Asian cutoff showed a higher prevalence of overweight and obesity, increased by $6.2 \%$ and $8.5 \%$ respectively.

Associated factors for thinness among this group of women when compared with the DHS 2006/07 showed similarities except for the inter district differences. Both studies show that the percentage of 'thin' women was significantly higher among those aged less than 30 years, especially among the teenagers, in the estate sector and in the lowest income group, and the poorest wealth quintile. In the present study, the districts of that showed high prevalence of thinness were: Ratnapura, Badulla and 
Nuwara Eliya. In the DHS 2006/07, high prevalence of thinness was reported from the districts of Moneragala and Matale which were not included in this study. Prevalence of overweight and/or obesity in women were significantly higher after 30 years of age, in the urban sector, Colombo MC and Colombo RD, and in the groups belonging to higher income levels and wealth quintiles. Similar observations were found in other studies carried out in Asia and other countries $(9,10)$.

In conclusion, among non pregnant and non lactating Sri Lankan women aged $15-49$ years, $17.0 \%$ are thin, $22.8 \%$ are overweight and $6.6 \%$ are obese; with half of women in the Colombo MC area being overweight or obese. Overweight or obesity was associated with increasing level of husband's education and higher wealth quintiles.

It is recommended that adult women should be screened for overweight or obesity periodically, especially during each health encounter and be offered appropriate counseling and referral. All overweight or obese women should be counseled about the health implications associated with their weight.

\section{Acknowledgements}

This study was supported by the UNICEF and WFP Colombo. The authors thank Dr. Dulitha Fernando, Dr. Upul Senarath and Indika Siriwardana for analyzing the data and for their support in preparing the detailed report of the study. We thank all staff of the Department of Nutrition for supporting the data collection.

\section{References}

1. http://www.who.int/gho/ncd/risk_factors/overweight_text/ en/index.html, accessed on 15.06.2012.

2. Department of Census and Statistics 2002. Sri Lanka Demographic and Health Survey 2000, Sri Lanka.

3. Department of Census and Statistics 2007. Sri Lanka Demographic and Health Survey 2006/7, Sri Lanka.

4. Katulanda P, Jayawardena MAR, Sheriff MHR, Constantine GR, Matthews DR. Prevalence of overweight and obesity in Sri Lankan adults. Obesity Reviews 2010; 11(11): 751-6.

5. Ministry of Healthcare and Nutrition 2011. National Nutrition Policy. Colombo.

6. World Health Organisation 1995. Physical status: the use and interpretation of anthropometry. Report of a WHO expert committee. WHO Technical Report Series 854. Geneva.

7. WHO expert consultation. Appropriate body mass index for Asian population and its implication for policy and intervention strategies. The Lancet 2004; 157-163.

8. Department of Census and Statistics 2008. Household Income and Expenditure Survey 2006-07. Colombo: Department of Census and Statistics.

9. Balarajan Y, Villamor E. Nationally representative surveys show recent increases in the prevalence of overweight and obesity among women of reproductive age in Bangladesh, Nepal, and India. J Nutr 2009; 139(11): 2139-44.

10. Odom JN. Overweight and obesity in women: a literature review. In: Partial Fulfillment of the Requirements for the degree of master of science in nursing in the Graduate College, The University of Arizona, 2006. 